\title{
Analisis Kepuasan Konsumen terhadap Pelayanan Barbershop dengan Metode Service Quality (Servqual) dan Importance Performance Analysis (IPA) Studi Kasus XYZ Barbershop
}

\author{
Achmad Odyk Akbar Nagara ${ }^{1}$, Andrean Emaputra ${ }^{2}$ \\ ${ }^{1,2)}$ Fakultas Teknologi Industri, Jurusan Teknik Industri, Institut Sains \& Teknologi AKPRIND \\ Jalan Kalisahak No. 28 Komplek BalapanYogyakarta \\ Email: odyknagara17@gmail.com, andrean.emaputra@akprind.ac.id
}

\begin{abstract}
ABSTRAK
XYZ Barbershop merupakan salah satu penyedia jasa pangkas rambut yang melayani shaving, cream bath, coloring, highlight, dan massage yang berlokasi di Yogyakarta. XYZ Barbershop berusaha memenuhi kepuasan dan keinginan konsumen atas produk yang ditawarkan dan kualitas pelayanan yang diberikan untuk bersaing dengan barbershop lain. Penelitian di XYZ Barbershop dilakukan untuk mengetahui kualitas dari pelayanan dan fasilitas yang diberikan. Penelitian ini menggunakan metode Service Quality (SERVQUAL) yang digunakan untuk mengidentifikasi atribut yang akan diteliti dan untuk mencari nilai kepuasan konsumen. Pembuatan kuesioner di metode SERVQUAL ini menggunakan 22 atribut kualitas yang dibagi ke dalam 5 (lima) dimensi. Metode Importance Performance Analysis (IPA) digunakan untuk mengelompokkan atribut menjadi kuadran prioritas utama, kuadran dipertahankan, kuadran prioritas rendah, dan kuadran berlebih. Nilai dari perhitungan SERVQUAL seluruh atribut masih berada dalam gap negatif. Hal ini menunjukkan bahwa kualitas pelayanan dan fasilitas yang diberikan XYZ Barbershop belum memenuhi harapan konsumen. Hasil pengelompokan diagram Importance Performance Analysis menghasilkan dua atribut yang berada pada prioritas utama, yaitu usaha tersebut harus meningkatkan keluasan dan keamanan tempat parkir serta memberikan berbagai macam pilihan model rambut, karena kedua atribut kualitas tersebut merupakan harapan konsumen sebagai prioritas utama agar dilakukan perbaikan.
\end{abstract}

Kata kunci: peningkatan kualitas, barbershop, Yogyakarta, SERVQUAL, importance performance analysis.

\begin{abstract}
XYZ Barbershop is a haircut service provider that provides shaving, cream bath, coloring, highlighting and massage, located in Yogyakarta. XYZ Barbershop strives to meet consumer satisfaction and desires for the products offered and the quality of service provided to compete with other barbershop. Research at XYZ Barbershop was conducted to determine the quality of the services and facilities provided. This study uses the Service Quality (SERVQUAL) method which is used to identify the attributes to be studied and to find customer satisfaction values. Making the questionnaire in the SERVQUAL method uses 22 quality attributes which are divided into 5 (five) dimensions. The Importance Performance Analysis (IPA) method is used to group attributes into the main priority quadrant, the maintained quadrant, the low priority quadrant, and the excess quadrant. The value of the SERVQUAL calculation of all attributes is still in a negative gap. This shows that the quality of service and facilities provided by XYZ Barbershop has not met consumer expectations. The results of the Importance Performance Analysis diagram grouping produce two attributes that are in the main priority, namely the business must increase the width and security of the parking lot and provide various choices of hairstyles, because these two quality attributes are consumer expectations as a top priority for improvement.
\end{abstract}

Keywords: quality improvement, barbershop, Yogyakarta, SERVQUAL, importance performance analysis.

\section{PENDAHULUAN}

Pada zaman modern ini persaingan perusahaan semakin meningkat tajam. Masyarakat semakin mudah dalam memperoleh informasi sehingga membuat gaya hidup masyarakat meningkat pesat. Hal ini membuat masyarakat semakin peduli dengan penampilan gaya rambut (hairstyles) dan berlomba-lomba untuk mengikuti tren masa kini. Semakin pesat pertumbuhan gaya rambut maka semakin pesat pula pertumbuhan perusahaan jasa di bidang pangkas rambut (barbershop). Barbershop ini merupakan inovasi atau perkembangan dari pangkas rambut biasa di tepi jalan dan dikemas lebih modern. keberadaan barbershop menunjukkan kondisi konsumen yang mana bukan hanya perempuan saja yang selalu memperhatikan penampilan, akan tetapi laki-laki juga memperhatikan penampilan. Selain pangkas rambut, laki-laki ketika di barbershop juga membutuhkan cuci rambut, pijat, dan perawatan rambut. 
Barbershop adalah salah satu Usaha Kecil dan Menengah (UKM) yang mempunyai peran penting dalam perekonomian Indonesia karena dapat menyediakan lapangan pekerjaan dan menghasilkan output yang berguna bagi masyarakat. Output tersebut tidak lepas dari kualitas pelayanan yang diberikan oleh barbershop kepada konsumen. Salah satu upaya untuk memenangkan persaingan ini, peningkatan kualitas secara terus-menerus sangat diperlukan dalam upaya mengikuti keinginan konsumen. Kualitas pelayanan yang tinggi adalah salah satu kunci keberhasilan dalam persaingan bisnis, karena kualitas pelayanan yang bagus menunjukkan produktivitas dan kemampuan menghasilkan kepuasaan konsumen. Perusahaan dikatakan sukses apabila peka terhadap apa yang diinginkan konsumen. Konsumen akan merasa nyaman dan ingin kembali lagi untuk menggunakan jasa perusahaan tersebut.

Servqual telah banyak digunakan untuk mengevaluasi barbershop. Pertama, konsumen Hunky Dory Barbershop menyatakan bahwa konsumen tidak mempersoalkan tingkat harga jika mereka merasa puas dengan barbershop tersebut dan semakin tinggi pelayanan yang diberikan maka konsumen akan semakin setia terhadap barbershop tersebut (Arifin, Hartoyo, \& Yusuf, 2020). Kedua, semakin baik kualitas dan persepsi harga yang diberikan oleh Barbershop ' $\mathrm{X}$ ' kota Padang maka semakin tinggi peluang konsumen untuk melakukan proses bisnis pada barbershop tersebut (Abdilla \& Husni, 2018). Ketiga, terdapat hubungan yang signifikan antara kualitas pelayanan dan loyalitas pelanggan (Tinamora, 2015). Keempat, Real7 Barbershop Yogyakarta sebaiknya lebih meningkatkan kenyamanan ruang tunggu dan kebersihan (Ardiansa, 2018). Kelima, kompetensi individu tidak berpengaruh signifikan terhadap kepuasan konsumen akan tetapi kualitas layanan berpengaruh signifikan terhadap kepuasan konsumen di Scoots Barbershop Masamba (Kasmi, 2019). Keenam, 27.7\% loyalitas pelanggan dipengaruhi oleh kualitas pelayanan customer relations (Simbolon \& Alfansyah, 2018). Ketujuh, untuk meningkatkan penjualan, seorang sales harus memperhatikan customer feeling dan customer perceptions (Islam, Nasira, Pritom, Paul, \& Reza-E-Rabbi, 2016). Kedelapan, persepsi harga, harga, dan kenyamanan sangat berpengaruh terhadap kepuasan konsumen yang sangat mempengaruhi customer loyalty (Setyanta, 2017).

Selain itu, beberapa hal telah ditemukan untuk meningkatkan kualitas layanan barbershop dengan Importance Performace Analysis. Kebersihan toilet, keadaan tempat ibadah, dan kepedulian karyawan terhadap keluhan pelanggan adalah hal-hal yang harus menjadi fokus perbaikan yang dilakukan oleh Emery Barbershop (Surianto, Lestari, \& Asdi, 2017). Vonnette Barbershop memberikan kinerja yang baik dalam hal empati, reliability, assurance, monetary price dan responsiveness yang sesuai dengan kepuasan pelanggan (Madja, Tumbuan, \& Pandowo, 2017).

XYZ Barbershop merupakan salah satu penyedia jasa pangkas rambut yang mengembangkan konsep pelayanan ramah, tempat yang nyaman, dan harga yang terjangkau. XYZ Barbershop berdiri sejak tahun 2012 dan sudah memiliki banyak cabang atau gerai di wilayah Yogyakarta dan Jawa Tengah. Potensi bisnis barbershop ini memang sangat menjanjikan, karena pangkas rambut dibutuhkan semua orang serta akan datang secara terus-menerus (periodik). XYZ Barbershop melayani shaving, cream bath, coloring, highlight, dan massage. Penelitian kualitas pelayanan dilakukan di salah satu gerai XYZ Barbershop yang berada di Jalan Nogorojo, Caturtunggal, Depok, Sleman, Daerah Istimewa Yogyakarta. XYZ Barbershop bukan satu-satunya barbershop yang berdiri dan beroperasi di sepanjang jalan Nogorojo. Ada empat barbershop yang menjadi pesaing XYZ Barbershop di sepanjang jalan Nogorojo. Barbershopbarbershop tersebut bisa dikatakan pesaing terberat XYZ Barbershop. Karena setiap waktu barbershop tersebut selalu ramai. Beda halnya dengan XYZ Barbershop yang ramai pada waktu atau jam tertentu saja.

Tren jumlah konsumen XYZ Barbershop mengalami penurunan dari bulan Januari sampai bulan Juli 2019 (Gambar 1). Penurunan konsumen tersebut disebabkan karena kualitas pelayanan dan fasilitas yang diberikan tetap (tidak ada perubahan) atau bahkan mengalami penurunan. Hal inilah yang menjadi landasan untuk melakukan penelitian di XYZ Barbershop selain belum ada penelitian tentang barbershop yang menggunakan metode IPA di Daerah Istimewa Yogyakarta (Emery Barbershop yang ada di kota Padang (Surianto et al., 2017) dan Vonnette Barbershop yang ada di kota Manado (Madja et al., 2017). Apa yang harus dibenahi atau ditingkatkan untuk dapat bersaing dengan barbershop lain. XYZ Barbershop tetap berusaha memenuhi keinginan konsumen dengan memprioritaskan kepuasan konsumen atas produk yang ditawarkan dan kualitas pelayanan serta didukung menguasai berbagai model potongan rambut pria yang up to date dan trendy. 


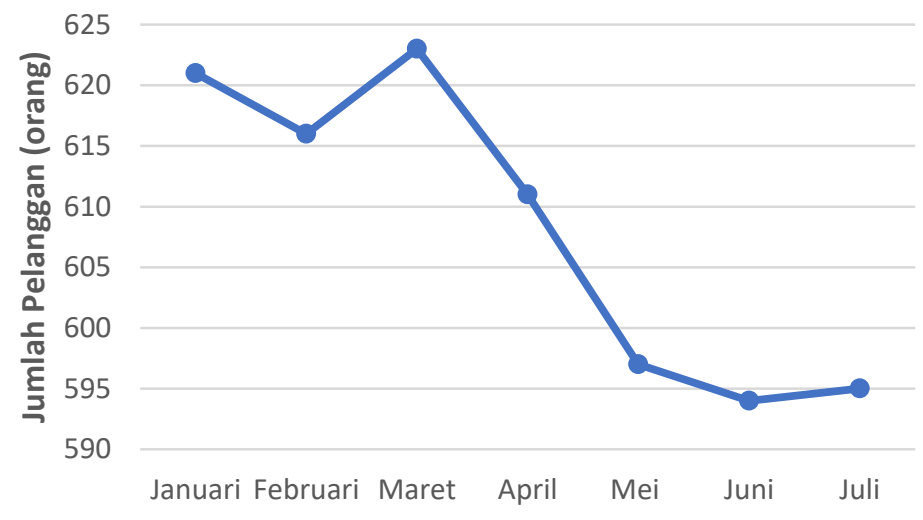

Gambar 1. Jumlah Pelanggan Barbershop dari Januari sampai Juli 2019

\section{METODE PENELITIAN}

Penelitian ini dilakukan dengan cara survei yang dilakukan pada konsumen XYZ Barbershop di Yogyakarta. Adapun jenis data yang digunakan yaitu data kualitatif yang terdiri dari jawaban responden terhadap variabel kualitas di barbershop tersebut (Tabel 1). Populasi dalam penelitian ini adalah seluruh konsumen XYZ Barbershop di Yogyakarta. Penentuan jumlah sampel dilakukan dengan Persamaan 1.

$$
n=\frac{z^{2}}{4(m o e)^{2}}
$$

dengan:

$\mathrm{n}$

$\mathrm{z}$

moe
: jumlah sampel

: nilai $\mathrm{Z}$ dengan tingkat keyakinan yang dibutuhkan penentuan sampel persen.

Pada $\propto=10 \%, Z=1.645$

: margin of error atau kesalahan maksimum yang bisa ditoleransi, biasanya $10 \%$.

$$
\begin{aligned}
& n=\frac{1.645^{2}}{4(0.1)^{2}} \\
& n=67.65
\end{aligned}
$$

Jumlah minimal sampel yang diambil adalah 67 sampel yang mewakili populasi yang ada yang kemudian dibulatkan menjadi 70 sampel. Pengambilan sampel dengan menyebar kuesioner berjumlah 70. Penyebaran tahap satu yakni sejumlah 30 kuesioner dan tahap kedua sejumlah 40 kuesioner. Kuesioner berisikan dua bagian. Bagian satu merupakan pembukaan dan petunjuk pengisian kuesioner untuk para responden, bagian kedua merupakan atribut-atribut kualitas yang akan dinilai tingkat kualitas yang dimiliki baik dari segi kenyataan maupun harapan. Responden pengisi kuesioner tersebut adalah konsumen yang pernah menggunakan jasa XYZ Barbershop atau konsumen yang kebetulan datang untuk melakukan pangkas rambut.

Tabel 1. Variabel kualitas yang diukur

\begin{tabular}{cl}
\hline No. & \multicolumn{1}{c}{ Atribut } \\
\hline & \multicolumn{1}{c}{ Tangible (bukti fisik) } \\
\hline 1 & XYZ Barbershop memiliki ruang tunggu yang nyaman \\
2 & XYZ Barbershop memiliki lokasi yang mudah dicari \\
3 & XYZ Barbershop memiliki kebersihan tempat yang baik \\
4 & XYZ Barbershop memiliki peralatan yang lengkap \\
5 & XYZ Barbershop memiliki tempat parkir yang luas dan aman \\
6 & XYZ Barbershop memiliki karyawan yang bersih dan rapi \\
7 & XYZ Barbershop memiliki toilet \\
8 & XYZ Barbershop memiliki pendingin ruangan (AC), TV, dan bacaan (koran, majalah, \\
9 & atau buku) \\
10 & XYZ Barbershop menyediakan nomor antrian \\
\hline
\end{tabular}


Tabel 1 (lanjutan). Variabel kualitas yang diukur

\begin{tabular}{|c|c|}
\hline No. & Atribut \\
\hline \multicolumn{2}{|r|}{ Reliability (keandalan) } \\
\hline 11 & XYZ Barbershop memberikan kemudahan dalam memilih model rambut \\
\hline 12 & XYZ Barbershop memberikan ketepatan dalam mencukur \\
\hline 13 & XYZ Barbershop memiliki peralatan yang baik dan modern \\
\hline \multicolumn{2}{|r|}{ Responsiveness (ketanggapan) } \\
\hline 14 & $\begin{array}{l}\text { Karyawan XYZ Barbershop menerima keluhan konsumen dengan cepat } \\
\text { dan tepat }\end{array}$ \\
\hline 15 & Kemampuan karyawan XYZ Barbershop dalam melaksanakan pekerjaan \\
\hline 16 & $\begin{array}{l}\text { Staff/karyawan XYZ Barbershop cepat dan tepat dalam memberikan informasi yang } \\
\text { dibutuhkan konsumen }\end{array}$ \\
\hline \multicolumn{2}{|r|}{ Assurance (jaminan atau kepastian) } \\
\hline 17 & Karyawan XYZ Barbershop professional kepada konsumen \\
\hline 18 & Karyawan XYZ Barbershop jujur \\
\hline 19 & XYZ Barbershop memberikan pelayanan yang ramah dan sopan terhadap konsumen \\
\hline \multicolumn{2}{|r|}{ Empathy (empati atau perhatian) } \\
\hline 20 & $\begin{array}{l}\text { Karyawan XYZ Barbershop menggunakan bahasa yang komunikatif dan mudah } \\
\text { dimengerti konsumen }\end{array}$ \\
\hline 21 & XYZ Barbershop berusaha mengerti keinginan dan kebutuhan konsumen \\
\hline 22 & $\begin{array}{l}\text { XYZ Barbershop memberikan pelayanan dan komunikasi yang sama kepada semua } \\
\text { konsumen tanpa terkecuali (pilih-pilih) }\end{array}$ \\
\hline
\end{tabular}

Hasil perhitungan dengan service quality (Tabel 4) digunakan sebagai dasar dalam pembuatan diagram Importance Performance Analysis (IPA). Nilai rata-rata kenyataan dari setiap item akan ditempatkan pada sumbu kinerja (sumbu $\mathrm{x}$ ) pada diagram IPA dan nilai rata-rata harapan dari setiap item akan ditempatkan pada sumbu harapan (sumbu y) pada diagram IPA (Gambar 2). Berdasarkan diagram IPA tersebut, maka item service quality yang ada pada Tabel 1 dapat dikelompokkan menjadi 4 bagian, yaitu, atribut prioritas utama yang sangat penting untuk ditingkatkan (kuadran A), atribut kualitas yang harus dipertahankan karena sudah baik (kuadran B), atribut kualitas yang memiliki prioritas rendah untuk dikembangkan lebih lanjut (kuadran C), dan atribut kualitas yang diberikan berlebihan kepada konsumen (kuadran D).

\section{HASIL DAN PEMBAHASAN}

\subsection{Uji Validitas dan Reliabilitas Kuesioner}

Uji validitas dilakukan untuk mencari $r$ hitung. Data yang digunakan adalah data masing-masing atribut (pertanyaan) dari data setiap responden (Tabel 2 dan 3). Hasil $r$ hitung yang didapat kemudian dibandingkan dengan $r$ tabel. Nilai $r$ tabel menggunakan jumlah sampel (n) 30 yakni penyebaran tahap satu dengan signifikasi $(\alpha) 10 \%$. Hasil $r$ tabel penyebaran tahap satu didapatkan $(\mathrm{df}=30-2=28)$ sebesar 0.3061 . Maka nilai $r$ hitung untuk variabel satu sebesar $0.549>0.3061 \mathrm{r}$ tabel. Kondisi tersebut menyatakan bahwa variabel tersebut valid.

Uji reliabilitas dilakukan untuk mencari nilai cronbach's alpha. Nilai cronbach's alpha yang didapat kemudian dibandingkan dengan nilai 0.6. Jika nilai cronbach's alpha > 0.6, maka kuesioner dinyatakan reliabel. Namun, jika nilai cronbach's alpha < 0.6, maka kuesioner dinyatakan tidak reliabel. Kuesioner kenyataan penyebaran pertama yang digunakan menghasilkan cronbach's alpha sebesar 0.903, maka kuesioner tersebut reliabel. Kuesioner harapan penyebaran pertama yang digunakan menghasilkan cronbach's alpha sebesar 0.866, maka kuesioner tersebut reliabel.

Tabel 2. Hasil Uji Validitas Kuesioner Kenyataan Penyebaran Pertama

\begin{tabular}{cccc}
\hline Variabel & r hitung & r tabel & Keterangan \\
\hline 1 & 0.549 & 0.3061 & Valid \\
2 & 0.480 & 0.3061 & Valid \\
3 & 0.375 & 0.3061 & Valid \\
4 & 0.436 & 0.3061 & Valid \\
5 & 0.428 & 0.3061 & Valid \\
6 & 0.563 & 0.3061 & Valid \\
7 & 0.642 & 0.3061 & Valid \\
8 & 0.393 & 0.3061 & Valid \\
\hline
\end{tabular}


Tabel 2 (lanjutan). Hasil Uji Validitas Kuesioner Kenyataan Penyebaran Pertama

\begin{tabular}{cccc}
\hline Variabel & r hitung & r tabel & Keterangan \\
\hline 9 & 0.660 & 0.3061 & Valid \\
10 & 0.533 & 0.3061 & Valid \\
11 & 0.515 & 0.3061 & Valid \\
12 & 0.807 & 0.3061 & Valid \\
13 & 0.473 & 0.3061 & Valid \\
14 & 0.613 & 0.3061 & Valid \\
15 & 0.708 & 0.3061 & Valid \\
16 & 0.716 & 0.3061 & Valid \\
17 & 0.657 & 0.3061 & Valid \\
18 & 0.628 & 0.3061 & Valid \\
19 & 0.672 & 0.3061 & Valid \\
20 & 0.735 & 0.3061 & Valid \\
21 & 0.614 & 0.3061 & Valid \\
22 & 0.583 & 0.3061 & Valid \\
\hline
\end{tabular}

Tabel 3. Hasil Uji Validitas Kuesioner Harapan Penyebaran Pertama

\begin{tabular}{cccc}
\hline Variabel & r hitung & r tabel & Keterangan \\
\hline 1 & 0.423 & 0.3061 & Valid \\
2 & 0.530 & 0.3061 & Valid \\
3 & 0.524 & 0.3061 & Valid \\
4 & 0.533 & 0.3061 & Valid \\
5 & 0.560 & 0.3061 & Valid \\
6 & 0.455 & 0.3061 & Valid \\
7 & 0.650 & 0.3061 & Valid \\
8 & 0.770 & 0.3061 & Valid \\
9 & 0.698 & 0.3061 & Valid \\
10 & 0.479 & 0.3061 & Valid \\
11 & 0.410 & 0.3061 & Valid \\
12 & 0.417 & 0.3061 & Valid \\
13 & 0.431 & 0.3061 & Valid \\
14 & 0.392 & 0.3061 & Valid \\
15 & 0.434 & 0.3061 & Valid \\
16 & 0.540 & 0.3061 & Valid \\
17 & 0.477 & 0.3061 & Valid \\
18 & 0.608 & 0.3061 & Valid \\
19 & 0.396 & 0.3061 & Valid \\
20 & 0.735 & 0.3061 & Valid \\
21 & 0,449 & 0,3061 & Valid \\
22 & 0.449 & 0.3061 & Valid \\
\hline
\end{tabular}

\subsection{Service Quality}

Metode Service Quality ini digunakan untuk mencari nilai gap (kesenjangan) kepuasan konsumen pengguna jasa pangkas rambut XYZ Barbershop. Perhitungan gap dengan Persamaan 2.

$$
Q=P(\text { Perceived Service })-E(\text { Expected Service })
$$


Tabel 4. Perhitungan Nilai Gap

\begin{tabular}{cccc}
\hline Atribut & $\begin{array}{c}\text { Rata-Rata } \\
\text { Kenyataan }\end{array}$ & $\begin{array}{c}\text { Rata-Rata } \\
\text { Harapan }\end{array}$ & $\begin{array}{c}\text { Nilai } \\
\text { Gap }\end{array}$ \\
\hline 1 & 2.97 & 3.71 & -0.74 \\
2 & 3.46 & 3.79 & -0.33 \\
3 & 3.59 & 3.81 & -0.23 \\
4 & 3.23 & 3.73 & -0.50 \\
5 & 3.10 & 3.80 & -0.70 \\
6 & 3.50 & 3.83 & -0.33 \\
7 & 2.94 & 3.73 & -0.79 \\
8 & 3.40 & 3.80 & -0.40 \\
9 & 1.84 & 3.50 & -1.66 \\
10 & 1.69 & 3.51 & -1.83 \\
11 & 3.17 & 3.83 & -0.66 \\
12 & 3.26 & 3.84 & -0.59 \\
13 & 3.40 & 3.89 & -0.49 \\
14 & 3.41 & 3.81 & -0.40 \\
15 & 3.56 & 3.90 & -0.34 \\
16 & 3.41 & 3.86 & -0.44 \\
17 & 3.44 & 3.83 & -0.39 \\
18 & 3.63 & 3.89 & -0.26 \\
19 & 3.49 & 3.84 & -0.36 \\
20 & 3.39 & 3.81 & -0.43 \\
21 & 3.43 & 3.93 & -0.50 \\
22 & 3.37 & 3.93 & -0.56 \\
\hline \multicolumn{5}{c}{ Jumlah } & -12.90 \\
\hline \multicolumn{5}{c}{ Rata-Rata } & -0.59 & \\
\hline
\end{tabular}

\subsection{Importance Performance Analysis (IPA)}

Metode Importance Performance Analysis (IPA) digunakan untuk mengkategorikan atau membagi keseluruhan atribut yang memiliki nilai gap negatif ke dalam diagram kartesius. Diagram kartesius tersebut memiliki empat kategori prioritas. Empat kategori tersebut adalah empat kuadran di dalam diagram IPA, yaitu: prioritas utama (Kuadran A), prioritas rendah (Kuadran C), pertahankan kualitas (Kuadran B), kualitas berlebih (Kuadran D). Data rata-rata kenyataan dan harapan (Tabel 4) diolah menggunakan IBM SPSS Statistic untuk diplot ke diagram kartesius atau diagram IPA (Gambar 2).

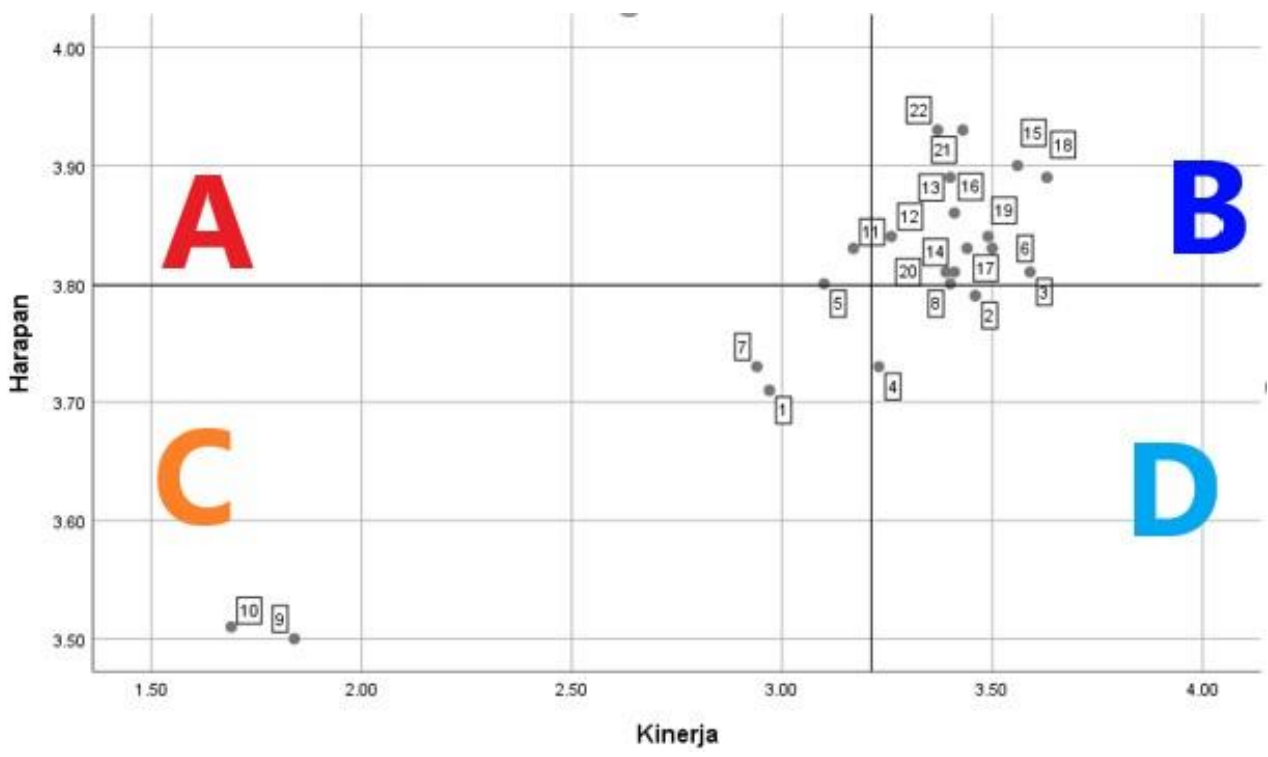

Gambar 2. Diagram Importance Performance Analysis (IPA) pada XYZ Barbershop 
Diagram Importance Performance Analysis dibuat untuk mengelompokkan seluruh atribut yang memiliki nilai gap negatif ke dalam empat kuadran. Diagram ini dibagi atas empat bagian yang dibatasi oleh dua buah garis yang berpotongan tegak lurus pada titik $(\mathrm{X}, \mathrm{Y})$ dengan $\mathrm{X}$ merupakan rata-rata tingkat kinerja atau kepuasan pelanggan seluruh faktor atau atribut dan $\mathrm{Y}$ adalah rata-rata dari skor rata-rata kepentingan atau harapan seluruh faktor yang mempengaruhi kepuasan pelanggan.

XYZ Barbershop memiliki dua atribut prioritas utama yang sangat penting untuk ditingkatkan (kuadran A). Pertama, XYZ Barbershop harus memiliki tempat parkir yang luas dan aman (atribut No. 5). Kedua, XYZ Barbershop harus memberikan kemudahan dalam memilih model rambut (atribut No. 11). Perbaikan dua atribut kualitas ini diharapkan dapat meningkatkan kepuasan konsumen sehingga konsumen dapat mengunjungi kembali barbershop tersebut. Hal tersebut berbeda dengan Emery Barbershop yang harus meningkatkan kualitas keadaan tempat ibadah yang berada pada kuadran A (Surianto et al., 2017) dan Vonnette Barbershop yang harus meningkatkan emotional response yang juga berada pada kuadran A (Madja et al., 2017). Kepuasan pelanggan tersebut diharapkan akan dapat meningkatkan loyalitas konsumen (Arifin et al., 2020; Setyanta, 2017; Tinamora, 2015).

XYZ Barbershop memiliki empatbelas atribut kualitas yang harus dipertahankan karena sudah baik (kuadran B). XYZ Barbershop memiliki tempat yang bersih (atribut No. 3). XYZ Barbershop memiliki karyawan yang bersih dan rapi (atribut No. 6). XYZ Barbershop memiliki pendingin ruangan (AC), TV, dan bahan bacaan (atribut No. 8). XYZ Barbershop memberikan ketepatan dalam mencukur (atribut No. 12). XYZ Barbershop memiliki peralatan yang modern (atribut No. 13). XYZ Barbershop menerima keluhan konsumen dengan cepat dan tepat (atribut No. 14). Karyawan XYZ Barbershop mampu melaksanakan pekerjaan (atribut No. 15). Staff/karyawan cepat dan tepat dalam memberikan informasi yang dibutuhkan konsumen (atribut No. 16). Karyawan XYZ Barbershop bersikap professional kepada konsumen (atribut No. 17). Karyawan XYZ Barbershop bersikap jujur (atribut No. 18). XYZ Barbershop memberikan pelayanan yang ramah dan sopan terhadap konsumen (atribut No. 19). Karyawan menggunakan bahasa yang komunikatif dan mudah dimengerti konsumen (atribut No. 20). XYZ Barbershop berusaha mengerti keinginan dan kebutuhan konsumen (atribut No. 21). XYZ Barbershop memberikan pelayanan dan komunikasi yang sama kepada semua konsumen tanpa terkecuali (atribut No. 22). Kualitas pelayanan XYZ barbershop ini sudah baik dibandingkan dengan Emery Barbershop karena kualitas pelayanan karyawan Emery Barbershop masih berada pada kuadran A yang berada pada prioritas utama yang kualitas atribut tersebut harus ditingkatkan secara terus menerus (Surianto et al., 2017).

XYZ Barbershop memiliki empat atribut kualitas yang memiliki prioritas rendah untuk dikembangkan lebih lanjut (kuadran C). Pertama, XYZ Barbershop memiliki ruang tunggu yang nyaman (atribut No. 1). Kedua, XYZ Barbershop memiliki fasilitas toilet (atribut No. 7). Ketiga, XYZ Barbershop menyediakan nomor antrian (atribut No. 9). Keempat, XYZ Barbershop menyediakan nota pembayaran (atribut No. 10). Kualitas pelayanan XYZ barbershop ini sudah baik dibandingkan dengan Emery Barbershop karena kualitas toilet Emery Barbershop masih berada pada kuadran A yang berada pada prioritas utama yang kualitas toilet tersebut harus ditingkatkan secara terus menerus (Surianto et al., 2017).

XYZ Barbershop memiliki dua atribut kualitas yang diberikan berlebihan kepada konsumen (kuadran D). Pertama, XYZ Barbershop memiliki lokasi yang mudah dicari (atribut No. 2). Kedua, XYZ Barbershop memiliki peralatan yang lengkap (atribut No. 4).

\section{SIMPULAN}

Seluruh item masih berada dalam gap negative. Hal ini menunjukkan bahwa kualitas pelayanan dan fasilitas yang diberikan XYZ Barbershop belum memenuhi harapan konsumen. Hasil dari pengelompokkan attribute dengan Importance Performance Analysis, yaitu: prioritas utama ada dua attribute, pertahankan kualitas atau prestasi ada empat belas atribut, prioritas rendah ada empat atribut, dan kategori berlebihan ada dua atribut. XYZ Barbershop harus memperbaiki attribute yang berada pada prioritas utama, yaitu, pertama, perusahaan harus memperbaiki keluasan dan keamanan tempat parkir, kedua, perusahaan harus memberikan pilihan model rambut yang lebih baik kepada konsumen. Konsumen sangat mengharapkan perbaikan dan peningkatan pada kedua attribut kualitas tersebut sehingga kepuasaan konsumen diharapkan juga dapat naik.

\section{DAFTAR PUSTAKA}

Abdilla, M., \& Husni, E. (2018). Pengaruh Persepsi Harga dan Kualitas Layanan terhadap Keputusan Pembelian Konsumen di Barbershop ' $\mathrm{X}$ ' Kota Padang. Menara Ekonomi, 4(1), 59-68. https://doi.org/10.1017/CBO9781107415324.004

Ardiansa, W. I. (2018). Analisis Kualitas Pelayanan terhadap Kepuasan Konsumen Real7 Barbershop 
Yogyakarta. Universitas Islam $\quad$ Indonesia. Retrieved from https://dspace.uii.ac.id/bitstream/handle/123456789/5660/SKRIPSI_Werdyan Indra Ardiansa $\% 2813311190 \% 29$.pdf? sequence $=1 \&$ is Allowed $=\mathrm{y}$

Arifin, M. F., Hartoyo, \& Yusuf, E. Z. (2020). The Importance of Service Quality in Building Customer Satisfaction and Loyalty in the Service Industry (A Case Study of Hunky Dory Barbershop). Binus Business Review, 11(2), 79-89. https://doi.org/10.21512/bbr.v11i2.6268

Islam, M., Nasira, S., Pritom, S. T., Paul, S. K., \& Reza-E-Rabbi. (2016). Influence of Interpersonal Relationship Skills in Salespersons' Service Performance: A Study on Hair Saloons \& Beauty Parlors of Bangladesh. IOSR Journal of Business and Management, 18(2), 77-90. https://doi.org/10.9790/487X-18217790

Kasmi. (2019). Pengaruh Kompetensi Individu dan Kualitas Layanan terhadap Kepuasan Konsumen Usaha Jasa di Scoots Barbershop Masamba. IAIN PALOPO. Retrieved from http://repository.iainpalopo.ac.id/id/eprint/1403/1/SKRIPSI KASMI.pdf

Madja, T. K., Tumbuan, W. J. F. ., \& Pandowo, M. (2017). The Analysis of Perceived Quality and Perceived Value Using IPA Analysis at Vonnette Barbershop in Manado. Jurnal EMBA: Jurnal Riset Ekonomi, Manajemen, Bisnis Dan Akuntansi, 5(02), 2508-2515. https://doi.org/10.35794/emba.v5i02.16732

Setyanta, B. (2017). Anteseden dan Konsekuensi dari Kepuasan Pelanggan: Survei Kepuasan Pelanggan Barbershop di Yogyakarta. Al Tijarah, 3(1), 29-44. https://doi.org/10.21111/tijarah.v3i1.937

Simbolon, D. P., \& Alfansyah, M. (2018). Pengaruh Kualitas Pelayanan Customer Relations terhadap Loyalitas Pelanggan (Survei pada Pelanggan di Lanang Barbershop Cabang Jakarta Barat). Pantarei, 2(2), 1-8. https://doi.org/10.1017/CBO9781107415324.004

Surianto, R. P., Lestari, R., \& Asdi, Y. (2017). Analisis Tingkat Kepuasan Pelanggan Emery Barbershop dengan Menggunakan Metode Customer Satisfaction Index dan Importance Performance Analysis. Jurnal Matematika UNAND, 6(3), 69-75. https://doi.org/10.25077/jmu.6.3.69-75.2017

Tinamora, L. R. (2015). Pengaruh Kualitas Pelayanan, Citra Merek, Kepuasan Pelanggan, dan Kepercayaan terhadap Loyalitas Pelanggan Barbershop di Karawaci, Tangerang. State University of Jakarta. Retrieved from http://repository.unj.ac.id/2068/1/SKRIPSI LISTYA RESMI TINAMORA 1.pdf 